This is a post-peer-review, pre-copy edited version of an article published in Families, Relationships and Societies. The definitive publisher-authenticated version will soon be available online.

\title{
Co-parenting arrangements in lesbian and gay families: when the 'mum and dad' ideal generates innovative family forms
}

\author{
Dr Cathy Herbrand \\ Reproduction Research Group \\ De Montfort University \\ Cathy.herbrand@dmu.ac.uk
}

\begin{abstract}
This paper engages with current debates on the potential of contemporary family formations, particularly those created by lesbian women and gay men, to challenge hegemonic family models. Drawing on in-depth interviews with lesbian and gay individuals living in Belgium, it explores parental ideals and family practices amongst people actively choosing 'coparenting arrangements' which include more than two adults raising a child. It examines how this route to parenthood was justified by co-parents' desire for a biological child, to experience pregnancy, to know the child's background and most importantly, to provide the child with a mother and a father. These motivations not only aimed at normalising their family situation but reflected deeply anchored family values. The paper demonstrates how innovative and reflexive family forms can arise from conventionally-based assumptions regarding gender roles and kinship, and calls therefore for a more nuanced consideration of individual values and intentions in parenting which potentially destabilise the hegemonic family model.
\end{abstract}




\section{Introduction}

This paper engages with current debates on the potential of contemporary family formations, particularly those created by lesbian women and gay men, to challenge hegemonic, heteronormative family models. Drawing on analysis of the rationale for choosing 'coparenting' provided by lesbian and gay individuals involved in such an arrangement, it seeks an improved understanding of the complex ways different family assumptions can simultaneously be challenged and reinforced (Mamo, 2007). The term 'co-parenting' refers here to the parental path, by which a man and a woman who are not a couple have a child that they will raise separately, with or without a partner. ${ }^{1}$ Although both biological parents are the child's legal parents, such arrangements often include more than two people who are actively involved even before the child's birth. In this paper, I use the term 'co-parents' to mean everyone involved in the arrangements, i.e. both biological parents and their partners. ${ }^{2}$ While co-parenting appears an increasingly common way for lesbian and gay individuals or couples to become parents (Cadoret, 2002; Jadva et al., 2015; Lewin, 2009; Weeks et al., 2001), research is still limited on this topic. An analysis of co-parenting arrangements offers an opportunity to understand the motivations and desires which shape such apparently novel and subversive multi-parental family formations. The paper explores how even potentially innovative and reflective parenting arrangements, such as co-parenting, can arise from conventionally-based ideas regarding gender roles and kinship, in particular the need for the presence of mum and dad in the child's life, something hitherto ignored in the literature.

\section{Background}

Over the last twenty years, lesbian and gay families have expanded and gained visibility in an increasing number of national contexts, contributing to the diversification of family forms and relationships (Beck and Beck-Gersheim, 1995; Giddens, 1992; Weeks et al., 2001; Weston, 1991). The ways and extent to which these forms have transformed dominant family ideals and power dynamics remain, however, under debate. 
Although the very idea of 'parenthood' for lesbian and gay people has been highly criticised for being too conformist or 'assimilationist' within radical queer politics and theory (Warner, 1999), sociological and anthropological works have instead described lesbian and gay family practices as challenging the hegemonic family model. Not only do people who identify as gay or lesbian appear to distance themselves from a biogenetic conception of relatedness (Dalton and Bielby, 2000), innovative and progressive 'families of choice', characterised by freedom and negotiation, are also common amongst gay and lesbian communities (Weeks et al., 2001; Weston, 1991). Lesbian parent families, in particular, are depicted as adopting non heteronormative practices in domestic task sharing (Dunne, 2000; Sullivan, 1996) which disrupt gendered parental roles (Donovan, 2000; Padavic and Butterfield, 2011). For some authors, lesbian and gay parents are therefore 'postmodern family pioneers' (Stacey, 2006, p. 28) and play a key role in social change by contesting mainstream values (Calhoun, 2000). This assumption has recently been challenged by scholars who have encouraged a more nuanced reading of these formations, by acknowledging the contradictions that may also arise with respect to power imbalances or the persistence of more traditional gendered roles (Gabb, 2004). Studies have also highlighted the complex navigation individuals make through a range of reproductive choices, parenting or family formulations (Almack, 2006; Lewin, 2009; Nordqvist, 2012), and how these solutions may simultaneously reinforce and challenge 'existing structures and forms of power and intimacy' (Mamo, 2007, p. 524).

This paper adds a further and novel dimension to this discussion by exploring the family ideals pursued by lesbian and gay people involved in co-parenting arrangements. It follows Lewin's approach of 'taking the objectives of ordinary lesbians and gay men seriously' (2009, p. 2) to gain a deeper and more complex understanding of their choices, dilemmas, and reasoning. The ways lesbian women and gay men perceive and pursue routes to parenthood is especially interesting because, as Nordqvist points out, 'the reproductive process requires couples to make explicit their choices about the family they seek to become' (2012, p. 646). It therefore offers a lens on the discourses, positionalities and values individuals operate within.

While a number of empirical studies have explored the aspirations and experiences of lesbian women using donor conception and their reasons for choosing an anonymous or a known donor (Almack, 2006; Donovan, 2000; Donovan and Wilson, 2008; Dunne, 2000; Haimes and Weiner, 2000; Luce, 2010; Mamo, 2007; Nordqvist, 2011), little is known about parental arrangements where the intention is to actively involve more than two adults in raising the 
child from the outset (Cadoret, 2002; Ryan-Flood, 2009). In addition, the biological father's or donor's motivations and views in these configurations are rarely investigated (Dempsey, 2012; Lewin, 2009). An analysis of the accounts of male and female co-parents therefore offers new and unique insights in this respect, especially since it highlights the situation of biological fathers who are recognised as the child's legal father in lesbian families.

The rest of this paper includes a description of the research context and methodology, before briefly presenting the main characteristics and innovative aspects of co-parenting practices represented in this study. This is followed by an overview of the four main motivations for co-parenting described in the interviews. These were: having a child's of one's own, experiencing pregnancy and breastfeeding, knowing the child's background, and most importantly, providing the child with a mother and a father. The paper concludes by calling for a more nuanced consideration of the diversity of family ideals and conceptualisations of kinship present amongst lesbian women and gay men; one which potentially contributes to the destabilisation of dominant assumptions about the constitution of family in LGBT (lesbian, gay, bisexual, and transgender) communities.

\section{Context and methodology}

The findings discussed here are drawn from a broader sociological research project on multiparenthood, which explored lesbian and gay co-parenting arrangements in Belgium (Herbrand, 2008). These family configurations offer a unique opportunity to examine formations of kinship and gender from various points of view ${ }^{3}$ : those of the father, the mother, and the respective partners. Examination of the motivations of lesbian and gay coparents is especially interesting in the Belgian context, where people have a number of options to access parenthood, including adoption, co-parenting, donor insemination and surrogacy, even though this last possibility is not yet regulated. ${ }^{4}$ Over the past 15 years, several laws in favour of LGBT rights have been adopted in Belgium, e.g. marriage and adoption became available to same-sex couples in 2006 and lesbian women have legally had access to reproductive technologies since 2007, even though these services were already widely offered prior to this. It is also possible for the non-biological mother to become the child's second legal parent if the child has been conceived through anonymous donor insemination. ${ }^{5}$ These legal changes were part of a set of liberal laws passed since 2003 in order to adapt the Belgian legal framework to current family configurations. Despite this 
progressive legal context, individual attitudes and institutional positions are more heterogeneous in practice, as Belgium, whilst a small country, is nevertheless characterised by significant geographical and politico-religious divides, as well as linguistic diversity.

The empirical data for this study were collected through extensive in-depth interviews (Herbrand, 2008). Given the need to contrast co-parents' respective views and to understand the negotiations and dynamics taking place between different members of the family, efforts were made to meet all co-parents involved in a joint family arrangement, which was possible in most cases, and to interview them separately. This method allowed each interviewee to provide their own account, un-inhibited by the presence of their partner or co-parent (Taylor and Vocht, 2011). Seven participants accepted to be interviewed on one or two further occasions between 2007 and 2010, so as to gain a better understanding of how their experiences of co-parenting had developed over time. Co-parents were accessed through snowball sampling, after regularly attending gay and lesbian association meetings and events related to the debate on adoption by same-sex couples taking place at the time in Belgium. A report on the political aspects of this debate by the author also facilitated contact with some co-parents (Herbrand, 2006).

In-depth interviews were carried out with 26 co-parents living in Belgium and speaking French. These accounts involved detailed analysis of nine distinct co-parenting cases, each including two to six co-parents. Most of the 11 children included in these cases were very young at the time of the research and were therefore not themselves interviewed.

$<$ Table 1 here>

Among the 26 participants, there were 11 women and 15 men, ranging between 28 and 52 years old. All but one co-parents were white. The majority had middle-class backgrounds and had acquired a middle or high level of education. ${ }^{6}$ Approximately half of them lived in an urban setting and half in a rural setting. Most co-parents involved in a joint arrangement tended to live in the same area, separated by five to 45 minutes driving, in order to facilitate the journeys between households. However, in one case, both parents lived a two-hour train journey apart from each other, in two different cities.

All interviews were transcribed verbatim, anonymised, and then thematically analysed (Silverman, 2001). Transcripts from each participant in a co-parenting arrangement were read and coded individually as well as being analysed in comparison to the other co-parents in that configuration in order to identify contrasts and overlaps in the accounts (Eisikovits and 
Koren, 2010). This provided data according to thematised individual accounts, as well as allowing a case by case analysis (Taylor and Vocht, 2011). An important effort was made to guarantee confidentiality during and after the interviews. In this paper, the intention is to explore the perceptions and motivations of lesbian and gay people who actively pursue coparenting. It therefore does not aim to contrast the views within the lesbian and gay couples. ${ }^{7}$ The study is based on an opportunistic sample and was not designed to represent a specific population but to maximise diversity regarding family structure, interactions and organisations among multi-parental family arrangements (Stake, 1994). The next section describes how co-parents reimagine and experiment with new family dynamics and arrangements, challenging some crucial features of the hegemonic nuclear family model.

\section{Co-parenting as innovative practice}

Co-parenting arrangements initially appear to represent a significant challenge to the nuclear and heterosexual family model. Indeed, beyond the fact of including gay and lesbian people, they often form complex multi-parental configurations whose structure and dynamics can vary greatly and which diverge widely from the heteronormative model. In this study, the majority of cases involved three co-parents: two composed of a lesbian couple and a single gay father (cases 4 and 5); three of a gay couple and a single woman (cases 6, 7 and 8). One case (case 3 ) included a gay couple and a lesbian couple. Two co-parenting cases were made up of two different child rearing arrangements and each involved three households (cases 1 and 2). The first comprised six co-parents (i.e. a lesbian couple and two gay couples) and the second five (i.e. a lesbian couple, a gay couple and a single gay man). There was also one coparenting arrangement including only the child's biological mother and father. This father was nonetheless living with a gay partner who was not part of the initial parental arrangements (case 9). All but one couple relationships originated prior to the decision to have children.

Not only do the individual co-parents spend a lot of time considering and planning their family situation as in other gay and lesbian family forms (Donovan and Wilson, 2008; Dunne, 2000; Mamo, 2007), but they also have to negotiate, implement and manage each aspect of this multi-parental arrangement between the biological mother, the biological father, and their respective partners. Intentionality is central in these very reflexive and personalised parental projects, in which each step tends to be thought-out and discussed 
between all the co-parents involved from the outset. This process is characterised by an absence of intervention from any social or medical institution, which leaves considerable leeway for co-parents to follow their preferences. Co-parents have thus to negotiate, create and legitimate the role each of them will play in the child's life, as well as to agree on the practicalities regarding the child's daily upbringing (e.g. the housing arrangements and the financial costs of child-rearing). 'Displaying family' was also crucial in co-parenting arrangements, where co-parents used various strategies to 'convey to each other and to relevant audiences that certain of their actions do constitute "doing family things" and thereby confirm that these relationships are "family" relationships" (2007, p. 67), for instance by sending out birth announcement cards where all the co-parents involved were mentioned. 'Displaying' in this way enabled the establishment of legitimacy as a family in public contexts. In so doing, co-parents question and transform parental experiences and family conceptions $^{8}$, as they 'forge ties and create meaning on their own terms and in ways that do not necessarily map neatly onto embedded logics of who and what makes a family' (Mamo and Alston-Stepnitz, 2015, p. 525).

One expectation that presents a particularly novel challenge to co-parenting is the need for a family to be located within a single household. Interestingly, co-parents in this study often stressed the unexpected advantages co-parenting brought to their life more generally, especially regarding the child's shared housing. Indeed, many co-parents, both men and women, said that, even if it was sometimes difficult to get used to it at the beginning, they eventually greatly appreciated the spare time they had when the child was not with them. It allowed them the ability to better balance parental and conjugal life knowing that the child is in a safe place. This system also allowed some co-parents who had variable or busy working lives to better manage professional and family life, by sharing and adapting their child's housing arrangements to professional constraints. This is why some families decided to repeat the arrangement: describing the second family arrangement as a 'copy-and-paste' of the first one. Thus, time can be devoted to their children but weekends or even weeks can be free for themselves. Co-parenting, which could seem marginal at first glance, was therefore well-adapted to current societal constraints and intense 'parenting culture' (Lee et al., 2014), allowing the implementation of innovative and flexible parental practices centred around the child. Both biological parents and often their partners were very dedicated to the child and tried to maximise their time with him or her when it was their turn. Whilst co-parenting arrangements are diverse, sometimes complicated and even conflicting, co-parenting may 
therefore appear as an attractive family model which contributes both to the bypassing of conventional family practices and present significant advantages for co-parents at various levels. However, these aspects of co-parenting were usually only discovered and appreciated by co-parents once they had experienced them in practice and were not part of the initial motivations which drove their decision to pursue this parental path. In order to demonstrate the complexity of the family situations included in the study, the case of family 2 is described here in more detail.

An example of co-parenting arrangements: Liz, Emma, Daniel, Anthony, Peter, Max and Jane

Liz and Emma have two children and although the children are raised as siblings by the lesbian couple during most of the week, they do not share any biological or legal tie. Each child has their own biological mother, Liz being the mother of Max and Emma the mother of Jane. But the children also have different fathers, Daniel (Max's father) and Peter (Jane's father), who are gay as well (but not a couple), and with whom the children separately spend most Wednesdays and every other weekend. This agreement was reached prior to the children's birth and included that each child's biological father would be recognised as their legal father, which means, among other things, that the children do not have the same last name. In Belgium, a child takes their father's last name, providing that the father recognises the child legally. This was the case in all the co-parenting arrangements included in the study. This case consists of five co-parents involved in two distinct child rearing arrangements. Liz and Emma both wanted children, and they decided to bear at least one each. However, Daniel, the gay man with whom Liz had her first child and his gay partner, Anthony, were not keen on having a second. Therefore, after both women talked it over, Emma approached Peter, another gay friend, whom they thought may be interested in becoming a father. Peter accepted and is now Jane's father.

This example demonstrates the kinds of complexities and novel practices at play in coparenting arrangements. The following section explores co-parents' initial motivations for pursuing these arrangements. 


\section{Co-parenting: conforming to hegemonic family ideals?}

In this study, contrary to what might be expected, co-parenting was not pursued as a more accessible option at a legal or financial level. It was quite clear that the participants chose this route to parenthood for other specific reasons and after giving it much consideration. In many cases, they could have opted for adoption or assisted medical reproduction, which are permitted in Belgium and could have been more convenient, at least for lesbian couples. In spite of those possibilities, they worked to achieve a family project in compliance with their values and identity. This section presents the four recurrent reasons given by participants to choose co-parenting and the rationale which surrounded them: the desires for a biological descent, to experience pregnancy, to know the child's background and most importantly, to provide the child with a mother and a father. Although some of these ideals are also important to other lesbian and gay individuals who achieved them by alternative parental routes (e.g. sperm donation or surrogacy), it was crucial for the co-parents in this study to have a mum and a dad involved in the child's life with whom he or she could develop significant and lasting relationships. The discourses through which co-parents' accounts are constituted reflect a powerful set of ideals associated with biogenetic relatedness and the heterosexual family.

\section{To have a child of one's own}

The need to have a biological child was a core theme in the interviews. Participants gave a number of reasons for this. Firstly because it was felt this was the main, if not the only way to create family 'bonds' and 'belonging'. The majority of co-parents regarded the biological tie as synonymous with 'genuine kinship'. This was especially perceptible through their refusal of adoption. For instance, Denis, whose co-parenting arrangement (case 4) was at the stage of conception, said that he could not consider adoption, even if the insemination did not work ${ }^{9}$ 'because I want it to be my child, and by that I mean a biological part of me'. This kind of argument was also present in Patrick's account:

If need be, I don't exclude adoption but I would first like to have a child who comes from myself, who really comes from my flesh, from my family lineage with all my background.... So, as far as I'm concerned, fulfilling the need I have to create life and to perpetuate my own lineage, well adoption is not going to be the answer (emphasis added). 
For Patrick, biological descent represents the main and most significant vector of transmission of biological substance, both at an individual and intergenerational level. It enables him not only 'to fulfil his need to create life' but also to 'perpetuate his own lineage' by transmitting something which comes from himself. The continuity of generations is regarded as passing through 'flesh'. The term 'flesh' is particularly meaningful here, as it reveals a conception of kinship based on the sharing of bodily substance. This relates to the ideology of 'consanguinity', whereby kin are defined as 'blood relations' and regarded as sharing substantial connection through blood (Franklin, 2013). Although the co-parents in this study did not usually refer to 'consanguinity' nor did they mention 'blood relations', some of them spoke of 'flesh' or 'biological part of oneself' to describe this substantial connection they wished to share with their child. While this conceptualisation of kinship has gradually been replaced by one which is based on genes in contemporary social discourses, it is still embedded in everyday talk and conveys a specific imaginary regarding origins, inheritance and family background (Nordqvist and Smart, 2014).

Given the difficulty for both partners of a same-sex couple to be genetically related to their child, it could be expected that gay and lesbian parents would be more open to 'social parenthood'. Many gay and lesbian activists have indeed challenged the biological definition of kinship with a discourse that prioritises the notion of choice in defining kinship over the notion of biology (Weston, 1991). This was especially the case at the time of the research when the adoption by same-sex couples was on the political agenda in Belgium (Herbrand, 2006). Although most co-parents believed this alternative should be available and some of them actively supported it, they said they would not have personally been happy with adoption to meet their need to reproduce and continue family lineage.

\section{To experience pregnancy and breastfeeding}

Having a 'biological child' through co-parenting was also highly valued by co-parents as it was associated with the possibility for lesbian women to carry and breastfeed a child. Different reasons were offered for this motivation. At a social level, getting pregnant was regarded as an opportunity to 'fit in' and to 'be like everyone else'. This concern was mentioned by Jessica, when she related the way she and her partner decided not to have a child through adoption: 
She [her partner] wanted to see me pregnant, she wanted us to have a child because she said: 'Why wouldn't you be pregnant while heterosexuals are? Anybody can adopt unhappy children'.

If this example reflects a desire of normalisation, it also implies, more deeply, a willingness to challenge, in a very visible way, the general opinion that homosexuality is incompatible with procreation.

At a more individual level, pregnancy was sought for the bodily contact it generated with the child through the mother's body. Several women had precisely chosen co-parenting instead of adoption because they wanted to have the experience of physical connectedness with the child. Marta, for instance, expressed a strong desire to 'feel the baby inside':

I wanted a biological child. Oh yes, it was obvious for me, I wanted a biological child.

Question: Why was it so important?

Because it just was... a visceral feeling. Yes, it is mine, it is really mine. He also belongs to Sam [the biological father], but I really felt this need as I've always said, I had this animalistic need, a basic need as mammals have, to feel a child inside my tummy (emphasis added).

Martha describes her desire for a child as irrepressible and deeply-rooted in her body: illustrating a vision of reproduction as a need; something founded by a natural order. This substantial connectedness to the child goes much further than that mentioned by the fathers, Denis and Patrick, described above. It encompasses an additional dimension for the mother by enabling her to experience this connectedness at a physical level. Pregnancy was perceived as allowing her to interact and exchange bodily substances with the fetus. This was seen to create a unique experience and a specific tie distinct from that based on genetics (Edwards, 2009).

This physical connection to the child was also valued and sought after by the female partners of several biological mothers. Three lesbian couples had indeed decided from the outset that each of the partners would successively bear a child. Not only would this counterbalance parental positions within the couple, but it would also enable both partners to satisfy their desire to have a child and to live this embodied experience. 
In several mothers' accounts, pregnancy was described as the positive characteristic of women over men, creating a special connection to the child before birth and offering closeness not available to the father. This argument usually accompanied a desire for mothers to breastfeed the child. Physical contact was maintained and some maternal body substance was passed to the child. In both male and female co-parents' accounts, pregnancy and breastfeeding were constructed as part of appropriate parenting, i.e. how things should be in compliance with some natural order.

Although this discourse may appear surprising when expressed in the context of lesbian identity, it appeared to reflect the importance granted to the mother 'bonding' through breastfeeding, an idea that has become increasingly salient over the past forty years (Faircloth, 2013).

\section{To know the child's background}

Having a biological child was also a way of knowing about the 'child's origins'. Although this notion often remained vague in co-parents' accounts, it could refer to particular identifying information regarding both biological parents or simply to a 'known background'. For most co-parents, it was unthinkable not to have access to this kind of information, because they believed it would be detrimental to the child's identity and development. This was the reason most female co-parents refused to use an unknown donor. This idea was expressed by Anne, a biological mother, when she said:

I couldn't picture myself saying to my child that it was with an unknown donor if he asked who his dad was. Would I have had the necessary elements to answer his question? The answer was no. [... ] He would miss a piece of the puzzle. I would have missed a piece of the puzzle. There are 5000 pieces. If you only have 4999, you will miss a piece of the puzzle that would enable you to say: this face, it's your father's (emphasis added).

The puzzle metaphor was used by Anne to describe information relative to the child's genetic and family history. Each 'piece of the puzzle' represents bits of information regarding the child; some specifically about paternal inheritance.

This metaphor is powerful as it implies that all information, either genetic or familial, needs to be available and correctly pieced together to achieve a sense of wholeness. Being aware of one's origins was regarded by most co-parents as a fundamental element of individual 
identity. Anne, like other co-parents, considered it her moral duty to possess and pass on this information. The issue of the child's identity was ubiquitous in the interviews, signaling widespread concern for retaining a sense of one's origins. Again, these ideas, which mainly derive from psychoanalysis and developmental psychology, illustrate broader social claims and discourse in favour of access to information about one's origins (Almack, 2006), which appeared to have influenced participants in their articulations and decisions about coparenting.

Knowing the child's origins was not only seen as important for contributing to a child's identity and wellbeing, it was also seen as crucial for providing information about his or her medical history, especially with regards genetic information; a concern which appears in other lesbian parents' accounts (Mamo, 2007; Nordqvist, 2011). This motivation also had other origins. For example, while Charlotte, the partner of Susan, expressed fear that their child could meet and fall in love with a genetically related child in the gay and lesbian community. The risk, she pointed out, was that 'they might therefore have a disabled child'. According to her, this was probable, because 'provided there is a good genitor, all the children run a risk a being conceived with the sperm of the same donor... They all go to the same hospital'. Since same-sex families tend to meet regularly with their children, she added, their children are likely to become friends. She concluded that the insemination was therefore 'out of the question':

You don't know what is being concocted behind the scenes. You don't know where the sperm comes from, who gives it... there are too many unknown factors, it's too much (emphasis added).

Charlotte's account encompasses a number of ideas regarding donor conception, clinical practices and relatedness. First, her rejection of donor conception, whether justified by medical or consanguinity concerns, conveys the fear of the unknown, which was shared by many co-parents, and reflected wider views in society. Indeed, 'with donor conceived children', Nordqvist and Smart explain, 'there is an apparent mystery, a kind of black hole made all the more significant by the modern emphasis on the foundational nature of genes' (2014, p. 161). This also reflects the feeling of uneasiness and creepiness towards 'phantom fathers' expressed by single mothers and lesbian mothers who used purchased sperm to conceive a child (Layne, 2013). In this case, the 'unknown' not only refers to the lack of information regarding the identity of the child's biological father but also conveys a sense of risk about the possible negative consequences of conceiving a child with someone and in 
unknown circumstances. This could either be the inheritance of potential diseases or 'negative features', or the possibility to be genetically connected to acquaintances. Her fear is enhanced by her perception of the Belgian gay and lesbian community as a 'small world'. It is also reinforced by the limited number of fertility clinics in Belgium and the fact that some of them are mostly used by lesbian couples.

At another level, Charlotte's fear of unknown consanguinity and incest highlights that her definition of kinship, as for many other co-parents, rested above all on biogenetic ties (Edwards, 2009). The widespread importance and salience of the 'genetic truth' amongst coparents reflects commonly shared ideas about genetic relatedness and inheritance, which has followed the rise and dissemination of the knowledge on genetics over recent decades (Franklin, 2013).

\section{To provide a mother and a father}

Above all, the co-parents in this study not only wanted to know who the child's biological parents were, but believed that the presence of a mother and a father was of utmost importance to the child. This was also the main motivation given by prospective gay and lesbian co-parents in other national contexts (Erera and Segal-Engelchin, 2014; Jadva et al., 2015). Finding a 'known donor' or an 'accessible surrogate' who could supply the child with information about origins was not sufficient. What many really wanted was for the child to be raised by both biological parents, as well as to have a legal mother and a legal father. This is the main reason participants gave for opting for co-parenting and spending a long time looking for potential co-parent(s). In order to comply with this ideal, all co-parents jointly decided for the biological father to always be recognised as the child's legal father, unlike most lesbian family situations accomplished by means of insemination with a known donor (Donovan, 2000; Haimes and Weiner, 2000; Mamo, 2007; Ryan-Flood, 2009). This helped the father play a significant and active parental role in the child's life both in terms of presence and decision-making. However, it also meant that the possible parents' partners could not have any legal parental position or rights towards the child, since legal parenthood is limited to two people in Belgium. The mother's partner could nonetheless have adopted the child if the biological father had not recognised the child, but this did not happen and in all cases the priority was granted to the child's father over the mother's partner in terms of legal rights. 
The need to have both biological parents present was mainly motivated by a desire to adhere to what was regarded as the 'normal', hegemonic family model, i.e. one that is based on the two sexually differentiated parental figures. According to co-parents, it was positive for the child to 'have his mum and dad as everyone else'. Tom said:

It might have to do with the conservative aspect of my personality but I still think that a child needs a dad and a mom. So, it might be very backward... Also with experience, I find that it is necessary. The child is bound to ask himself questions anyway. He sees 'mum and dad' around him and therefore, he wants to know who dad is and who mum is and I couldn't picture myself raising a child with my partner without the mum (emphasis added).

Even if this father felt it might be regarded as 'backward' or 'traditional', he felt compelled, like other co-parents, to provide the child with a family structure in compliance with the socially and legally dominant model, which was also the family model he himself valued. This was felt to help the child's well-being and social integration. Patrick, another biological father, explained:

A mother and a father, I think it's not essential, but whenever possible, it makes it easier for the child. [...] Especially with regard to the outside world, it gives a somewhat more traditional picture and it enables the child to avoid problems he would otherwise encounter outside with regard to other children at school, or to neighbours, or things like that (emphasis added).

Like other co-parents, Patrick believed that the child would gain social acceptance by knowing and being raised by both a mother and a father. It would not be a further source of stigmatisation, even while the child was being raised by gay and lesbian parents. The same kind of arguments were used by lesbian mothers using donor conception to justify their decision to select a donor of similar 'race', so as to avoid making the child 'more different than they already were' (Nordqvist, 2012, p. 651).

This co-parental family structure also allowed both biological parents to describe themselves, if they wished to do so, as a heterosexual parental couple, for instance at the child's school or at their work place. If they were asked questions, they could mention the child's other parent, whom most people assumed to be an ex-partner. This configuration thus helped normalise what could otherwise be seen as deviant by concealing their gay or lesbian identity. Although 
most people I interviewed were often 'out' or publically open regarding their homosexuality, 'passing', i.e. 'the ability to be recognised by others as someone different from "who you are" (Mamo, 2007, p. 69), was still an important requirement in specific spheres of coparents' lives.

Apart from social conformity, co-parents also emphasised the importance of having a mother and father who would contribute to create specific relationships with the child. However, most participants generally had trouble explaining and justifying why having both parental figures was so important. For example, when Sam was asked what he thought differentiates the mother from the father, he said, 'I don't really know (silence). It's the pattern I've always been confronted with'. Like Sam, other co-parents usually gave hesitant and ambivalent answers. Or, some referred to what they experienced during their own childhood, either the importance of having a present father or the suffering caused by an absent parent. Emma, a biological parent's partner (case 2), developed her reasoning by saying:

With respect to myself, I made my own soul searching and I really needed my dad, at least he was there. I'm sure that I would probably have managed without him but I know that it is important for me the fact that I had a dad.

The gender distinctions made by the co-parents between parental roles was perceptible through the fact that most of them felt that being a same-sex couple was not sufficient to raise a child. Indeed, their accounts often conveyed a tension as far as gender was concerned. Whereas most co-parents usually took or defended egalitarian positions regarding men and women as well as straight and gay people, they had difficulties viewing parental roles and identities as equivalent. Co-parents' desire to bypass sexual differences came often against their belief that being raised by a mother and a father was necessary.

It seemed particularly obvious for the gay men that a child definitely needed a mother, which was the reason they would not have thought to go for surrogacy. Moreover, most co-parents shared the view that the children needed their mother more than their father, revealing the persistence of heteronormative assumptions. Peter, for instance, was initially worried that he would not see much his child in the first months because the baby would stay with the mother during this period to facilitate breastfeeding. Then, he eventually convinced himself that it was the best thing for the child:

In retrospect, I realise that it is important for a child to be with his mother

in the beginning. Whether it is a boy or a girl, it's important. Let's be honest 
about that, the link is really strong with the mum from the beginning. And frankly, I believe it is a good arrangement (emphasis added).

As in other examples, the mother is perceived as playing a dominant role in the child's life, not only because of a more 'natural' ability to take care of the child but also because of the special physical bond she has with the child, something that the father is seen as lacking.

Whereas the mother's presence was often taken for granted, the father's role was regarded as specific and necessary, which was contrary to findings elsewhere where parenting was not dependent on gender or sex identity (Donovan, 2000; Haimes and Weiner, 2000). The male genitor was represented not as a 'donor' but as the 'father'.

Moreover, none of the biological parents' partners were called 'mum' or 'dad' or identified themselves as such. Indeed, participants' focus on biogenetic relatedness and on the motherand-father figures led them to clearly differentiate the biological parents from their respective partners. This was even the case when these partners became involved with the child to the same extent as the biological parent. Almost all participants considered there to be only one 'mother' and 'father' and that the biogenetic tie to the child granted a privileged status. These observations illustrate how kinship and gender are closely linked via their mutual grounding in everyday ideas about sex based biological differences (Collier and Yanagisako, 1987).

\section{Conclusion}

This study is the first to explore parental ideals and family practices amongst both lesbian women and gay men actively choosing to co-parent a child in arrangements featuring more than two adults. The findings provide a rich understanding of co-parents' conceptions of kinship, which appeared to be deeply rooted in a biological logic and linked with a perceived differentiation of gendered parental roles. These formulations held a special significance for co-parents, even when it was felt that these ideas might be regarded as 'old-fashioned'. Mediated through and reinforced by the current cultural significance afforded to motherhood, genes, and access to information about one's own origins, they were shared by the majority of the co-parents in this study. These accounts illustrate the persistent influence of ideologies of the biological and heteronormative family model, even within diverse social contexts. 
Although the co-parents in this study are not representative of all lesbian and gay people, and in fact, at present represent only a small minority, these cases demonstrate the diversity of attitudes and experiences which exist among LGBT communities and the need to acknowledge these ideals as reflective of a range of needs and aspirations. This diversity is still too often ignored, dismissed, regarded as a 'failure of the queer movement' (Dahl, 2014) or incorporated to the broad category of 'homonormativity' (Duggan, 2002).

The articulation of biological relationships and differentiated parental figures both reflected the family model to which co-parents adhere and was drawn on as a means to normalise their own family situation, which might otherwise be seen as alternative or unconventional. It confirms the pressure experienced by gay and lesbian people to 'fit in' when children are involved (Nordqvist, 2012, p. 658) and thus to acquire social and political inclusion and legitimacy (Mamo, 2007), whilst adding a new dimension to LGBT scholarship.

While much existing work has emphasised the 'subversive potential' of lesbian and gay parents, the findings presented above nuance this image and show that some lesbian and gay people can deliberately value and adopt conventional family ideals, while simultaneously implementing and living in innovative family configurations. This reasoning was also present amongst co-parents in favor of sex equality and who were experimenting with more egalitarian divisions of housework and parental duties. These findings therefore support some authors who suggest we need to be 'wary of overemphasising the progressive potential of lesbian family forms' (Gabb, 2004; Lewin, 1993; Padavic and Butterfield, 2011, p. 194).

Co-parents' conventional family ideals do not prevent them, however, from reimagining kinship and living de facto new family forms. They do indeed contribute, more or less willingly, to the calling into question of hegemonic family models and the experimentation with and legitimation of new family practices, in particular by raising children outside the nuclear context and through personalised and flexible parental arrangements. In this study, the challenging parental practices described were nonetheless often the result of efforts to comply with and to reproduce conventional ideals, rather than to contest and transform dominant family assumptions, as is regularly suggested in the literature. This calls for a more nuanced analysis of contemporary family formations, which considers seriously the diversity of individual values and intentions, while examining the various ways in which achieving these goals can destabilise the hegemonic, heteronormative family model. 


\section{Acknowledgements}

The research presented here was funded by the Belgian National Scientific Research Funds (F.R.S.-FNRS). I would like to thank the colleagues who have provided helpful feedback and suggestions on early drafts. I am especially grateful to Carrie Friese, Nicky Hudson and Frederic Malherbe for their valuable insights and constant encouragements. Finally, thank you to the families who volunteered their time to take part in the research.

\section{Notes}

1. The term 'co-parenting' is used differently according to the context and the discipline. The concept was initially coined by psychologists and legal experts to describe shared parenting by both parents after a separation. In the context of gay and lesbian families, it increasingly refers to the arrangement of conceiving and raising a child between a man and a woman who are not a couple (Cadoret, 2002; Lewin, 2009). The term 'co-parent' is also used to designate the same-sex partner of the child's biological and/or legal parent, which can cause some confusion.

2. I use the terms 'parents', 'mother' or 'father' to designate only the biological and legal parent(s) and to differentiate them from their partners.

3. The analysis presented here focuses specifically on the participants' rationale and motivations for choosing co-parenting. Other themes emerging from the study (i.e. family relatedness, multi-parenthood or gender relationships) are, and will be, reported elsewhere (Herbrand, 2015).

4. Surrogacy is not legally regulated and potential fathers have some leeway with respect to arrangements.

5. The 2006 law permitted the non-biological mother to adopt the child of her partner conceived by donor insemination. Since January 2015, the non-biological mother is directly recognised as the child's second mother if the couple is married. Otherwise, the nonbiological mother can legally recognise the child after birth.

6. I acknowledge the limits of the sample which, as in many studies on lesbian and gay parents (Gabb, 2004), includes mostly white, educated and middle class participants. An 
implication of this may be that these participants are precisely more inclined to value and implement hegemonic family values.

7. Extracts from the biological parents' interviews dominate the quotations presented in this paper as it was often those individuals who were leading the project and made the important decisions.

8. This topic is in preparation for publication elsewhere.

9. In nearly every co-parenting arrangement, conception was made by so-called 'selfarranged insemination'.

\section{References}

Almack, K., 2006. Seeking sperm: accounts of lesbian couples' reproductive decision-making and understandings of the needs of the child. Int J Law Policy Family 20, 1-22.

Beck, U., Beck-Gersheim, E., 1995. The normal chaos of love. Polity Press, Cambridge.

Cadoret, A., 2002. Des parents comme les autres. Homosexualité et parenté. Odile Jacob, Paris.

Calhoun, C., 2000. Feminism, the family, and the politics of the closet: lesbian and gay displacement. Oxford University Press.

Collier, J.F., Yanagisako, S., 1987. Gender and kinship: essays toward a unified analysis. Stanford University Press, Stanford.

Dahl, U., 2014. Not Gay as in Happy, but Queer as in Fuck You: Notes on Love and Failure in Queer(ing) Kinship. Lambda Nordicas 143-168.

Dalton, S.E., Bielby, D.D., 2000. "That's our kind of constellation": lesbian mothers negotiate institutionalized understandings of gender within the family. Gender \& Society 14, $36-61$.

Dempsey, D., 2012. More like a donor or more like a father? Gay men's concepts of relatedness to children. Sexualities 15, 156-174.

Donovan, C., 2000. Who needs a father? Negotiating biological fatherhood in British Lesbian families using self-insemination. Sexualities 3, 149-164. 
Donovan, C., Wilson, A.R., 2008. Imagination and integrity: decision-making among lesbian couples to use medically provided donor insemination. Culture, health \& sexuality: an international journal for research, intervention and care 10, 649-665.

Duggan, L., 2002. The new homonormativity: the sexual politics of neoliberalism, in: Castronovo, R., Nelson, D.D. (Eds.), Materializing Democracy: Towards a Revitalized Culturl Politics. Duke University Press, Durham, NC, pp. 173-194.

Dunne, G., 2000. Opting into motherhood : lesbians blurring the boundaries and transforming the meanings of parenthood and kinship. Gender \& Society 14, 11-35.

Edwards, J., 2009. The matter in kinship, in: European Kinship in the Age of Biotechnology. Berghahn Books, New York \& Oxford, pp. 1-18.

Eisikovits, Z., Koren, C., 2010. Approaches to and Outcomes of Dyadic Interview Analysis. Qualitative Health Research 20, 1642-1655.

Erera, P.I., Segal-Engelchin, D., 2014. Gay Men Choosing to Co-Parent with Heterosexual Women. Journal of GLBT Family Studies 10, 449-474.

Faircloth, C., 2013. Militant Lactivism? Attachment Parenting and Intensive Motherhood in the UK and France. Berghahn Books, New York.

Finch, J., 2007. Displaying Families. Sociology 41, 65-81. doi:10.1177/0038038507072284

Franklin, S., 2013. From blood to genes? Rethinking consanguinity in the context of geneticization, in: Johnson, C.H., Jussen, B., Sabean, D.W., Teuscher, S. (Eds.), Blood and Kinship: Matter for Metaphor from Ancient Rome to the Present. New York and Oxford, pp. 285-306.

Gabb, J., 2004. Critical differentials: querying the incongruities within research on lesbian parent families. Sexualities 7, 167-182.

Giddens, A., 1992. The transformation of Intimacy. Sexuality, Love, and Eroticism in Modern Societies. Polity Press, Cambridge, UK.

Haimes, E., Weiner, K., 2000. "Everybody”s got a dad...' Issues for lesbian families in the management of donor insemination. Sociology of Health \& Illness 22, 477-499.

Herbrand, C., 2015. Comprendre le besoin de reconnaissance légale en matière de pluriparentalité : pistes de réflexion à partir des coparentalités gaies et lesbiennes. Canadian Journal of Women and the Law/Revue Femmes et Droit 27, 71-93. 
Herbrand, C., 2008. Les normes familiales à l'épreuve du droit et des pratiques: analyse de la parenté sociale et de la pluriparentalité homosexuelles. Doctoral thesis, Université Libre de Bruxelles, Bruxelles.

Herbrand, C., 2006. L'adoption par les couples de même sexe. Courrier hebdomadaire du CRISP (Centre de Recherche et d'informations sociopolitiques) 72p.

Jadva, V., Freeman, T., Tranfield, E., Golombok, S., 2015. "Friendly allies in raising a child": a survey of men and women seeking elective co-parenting arrangements via an online connection website. Hum. Reprod. 30, 1896-1906.

Layne, L.L., 2013. "Creepy", "freeky", and "strange": How the "uncanny" can illuminate the experience of single mothers by choice and lesbian couples who buy "dad." Journal of Consumer Culture 13, 140-159.

Lee, E., Bristow, J., Faircloth, C., Macvarish, J. (Eds.), 2014. Parenting Culture Studies. Palgrave Macmillan, Basingstoke and New York.

Lewin, E., 2009. Gay fatherhood: narratives of family and citizenship in America. The University of Chicago Press, Chicago and London.

Lewin, E., 1993. Lesbian mothers: accounts of gender in American culture. Cornelle University Press, Ithica.

Luce, J., 2010. Beyond expectation: lesbian/Bi/queer women and assisted conception. University of Toronto Press, Toronto.

Mamo, L., 2007. Queering Reproduction: Achieving Pregnancy in the Age of Technoscience. Duke University Press, Durham, NC.

Mamo, L., Alston-Stepnitz, E., 2015. Queer Intimacies and Structural Inequalities New Directions in Stratified Reproduction. Journal of Family Issues 36, 519-540.

Nordqvist, P., 2012. "I don"t want us to stand out more than we already do': Lesbian couples negotiating family connections in donor conception. Sexualities 15, 644-661.

Nordqvist, P., 2011. "Dealing with sperm": comparing lesbians' clinical and non-clinical donor conception processes. Sociology of Health \& Illness 33, 114-129.

Nordqvist, P., Smart, C., 2014. Relative Strangers: Family Life, Genes and Donor Conception. Palgrave Macmillan. 
Padavic, I., Butterfield, J., 2011. Mothers, Fathers, and "Mathers": Negotiating a Lesbian CoParental Identity. Gender \& Society 25, 176-196.

Ryan-Flood, R., 2009. Lesbian motherhood. Gender, families and sexual citizenship. Palgrave Macmillan, Basingstoke.

Silverman, D., 2001. Interpreting qualitative data. Sage, London.

Stacey, J., 2006. Gay Parenthood and the Decline of Paternity as We Knew It. Sexualities 9, $27-55$.

Stake, R.E., 1994. Case Studies, in: Denzin, N.K., Lincoln Yvonna S. (Eds.), Handbook of Qualitative Research. Sage, Thousand Oaks, pp. 236-247.

Sullivan, M., 1996. Rozzie and Harriet? Gender and family patterns of lesbian coparents. Gender and Society 10, 747-767.

Taylor, B., Vocht, H. de, 2011. Interviewing Separately or as Couples? Considerations of Authenticity of Method. Qual Health Res 21, 1576-1587.

Warner, M., 1999. The Trouble with Normal: Sex, Politics and the Ethics of Queer Life. Harvard University Press, New York.

Weeks, J., Heaphy, B., Donovan, C., 2001. Same sex intimacies: families of choice and other life experiments. Routledge, London.

Weston, K., 1991. Families we choose: lesbians, gays, kinship. Columbia University Press, New York. 